\title{
Leaping through Hurdles: Adaptability among Female Athletes
}

\author{
Arvin A. Andacao*, Carla Jane B. Linganay \\ Davao Oriental State College of Science and Technology, Davao Oriental, Philippines
}

Received May 9, 2021; Revised June 16, 2021; Accepted July 22, 2021

\section{Cite This Paper in the following Citation Styles}

(a): [1] Arvin A. Andacao, Carla Jane B. Linganay, "Leaping through Hurdles: Adaptability among Female Athletes," International Journal of Human Movement and Sports Sciences, Vol. 9, No. 4A, pp. 45 - 52, 2021. DOI: 10.13189/saj.2021.091308.

(b): Arvin A. Andacao, Carla Jane B. Linganay (2021). Leaping through Hurdles: Adaptability among Female Athletes. International Journal of Human Movement and Sports Sciences, 9(4A), 45 - 52. DOI: 10.13189/saj.2021.091308.

Copyright $@ 2021$ by authors, all rights reserved. Authors agree that this article remains permanently open access under the terms of the Creative Commons Attribution License 4.0 International License

\begin{abstract}
Background: Basketball is a popular team sport played mostly by men. However, female athletes are quite daunting to play. Aims: This study was designed to explore and unveil the adaptability among female athletes in playing basketball. Settings and Design: Using the qualitative and interpretive orientation research, the study employed a phenomenological approach with ladies' varsity and athletes in the Davao Oriental State College of Science and Technology. Methods and Material: The researchers utilized a validated content and conducted interview guide schedule prior to obtain the investigated data from the informants through in-depth interviews and focus group discussion techniques. Statistical analysis used: Thorough transcription, careful translation, and appropriate decoding of data were conducted before the generation of the interview results operating the NVivo 12 software. Results: The findings of the study indicated that adaptability occurred when there was a need for change. Time-management, focus, conflicts among teammates and coaches, and physical qualities were recognized as problems and challenges by the informants. Identified limitations brought negative interconnected effects from their academics, athletics, and social relationships in which athletes self-assess for obtaining poor performance. Focus and adjusting are a few of the essential elements as a resolve to overcome hurdles. Conclusions: Finally, adaptability varies depending on the perception and the range of the experience of the athletes. Few of the informants have been now not all successful in overcoming playing basketball. Moreover, the authors recommend the RID Adaptation Framework as a guide for the athletes to
\end{abstract}

play and future researchers for further investigation and improvement of this context.

Keywords Adaptability, Basketball, Female Athletes, Phenomenological Approach, Philippines Sports Management

\section{Introduction}

Basketball has become a popular sport played all around the world generally by men. It is a sport requiring high aerobic and physical resources to play. However, basketball has also been participated by women though the sport is masculine in nature and physically robust due to body contact activities. These actions are vital in the adaptability of the female student-athletes in engaging and playing basketball. Adaptability focuses on how the students take new challenges and adjust to uncertain circumstances like class participation, school enjoyment, positive academic intentions, self-esteem, life satisfaction, and sense of meaning and purpose [1]. Likewise, for an athlete to stay novel and thriving in the field of basketball, it must adapt effectively to new developments and embrace the new environment [2].

Women face many hurdles to participating in sports, which prevent them from reaping the many benefits that can be gained [3]. Most problems faced by college female athletes while playing basketball were verbal aggression [4], sexual harassment [5], social adjustments [6], 
relationship with coaches [7,8], academics challenges [9], menstrual disorders [10], training and competition stresses [11], and body composition [12]. Student-athletes were required to have careful balancing of stress and recovery for optimum adaptation with all the demands of additional requirements of an academic program [13]. Women have become more rampantly involved and successful in sports, but the function of adaptability in women does not treat comparable levels of attention [14]. With all these circumstances and considering no study yet conducted in the Davao Oriental State College of Science and Technology (DOSCST), the authors were eager to investigate the internal replications and diversions among the female athletes that limited their sporting performance and their coping mechanisms on how they deal with their own limitations. This study also addressed the gap of the research particularly few of the women are involved and not given preferential time and priority in sports.

The aim of the study was to explore and unveil the college female athletes' adaptability, specifically in playing basketball. In doing so, we would like to establish a conceptual framework or model out from the gathered information of the study. The lens of this study was anchored on the theory of Individual Adaptability also known as I-ADAPT which described the ability of individuals to accept the various tasks, social circumstances, and milieu structures [15]. Several authors and scholars supported adaptability in many forms such as personal resource [16], academic and non-academic outcomes [1], normative sporting transition [17], physiological strength training programs $[11,18]$, and teamwork [19]. The authors conceptualized that adaptability is the backbone of female athletes in DOSCST on how to overcome their experiences, struggles, and unforeseen circumstances in playing basketball despite being vulnerable as women.

\section{Subjects and Methods}

The study is qualitative research in nature which was primarily concerned with understanding human beings' experiences in a humanistic and interpretive approach [20]. This paper specifically employed a phenomenological approach that the researchers tried to capture the phenomena (personal and social experiences and events) through how female college athletes adapt to playing basketball and their performances.

The informants of the study were female basketball varsity and athletes of DOSCST. The research location was strategically situated in the Guang-guang, Dahican, the City of Mati, the south-easternmost part of Mindanao, Philippines $\left(6.9323^{\circ} \mathrm{N}, 126.2537^{\circ} \mathrm{E}\right)$. There were ten (10) athletes involved in the in-depth interview (IDI) and another ten (10) athletes who participated in the focus group discussion (FGD). This study made use of purposeful sampling, specifically the homogeneous sampling method [21].

The Interview Guide Schedule as guide questions was prepared. This instrument was content validated and tested on a few participants to ensure the readiness of the tool. The prepared tool has been sought to reveal their problems as well as on how they adapt to the nature of playing basketball.

The researchers asked approval first to conduct the dialogue and obtain an updated list of female basketball athletes in the Office of the Sports Development Director. All the registered athletes were contacted and asked permission with informed consent to participate voluntarily in the investigation. We met them one by one and were freely asked to suggest their desired schedule and venue for the interview where they felt more at ease in their surroundings and thereby allowed them to speak more easily and openly on the research topic.

We appropriately observed the universal human protection ethical standards for research and the Data Privacy Act for the informants. During the courtesy meeting, our identities and affiliations as researchers were properly introduced. We justly informed the purpose of the study and the significant reasons for the conduct of the interview. We also assured the female athletes that no one will harm and refuse anytime if they withdraw to participate in the study. Their identities were classified as they utilized pseudonyms. The athletes were aware of the use of an audio-voice recording to collect their responses. Each athlete was given a preferred time and asked a similar set of questions to their overall experiences of adapting to hindrances and the impact it had on their sporting performance.

The gathered IDI and FGD were saved to the computer with a password. We critically listened and analytically transcribed the audio-recordings. Translated data were generated since the investigation is open and free to use their native tongue. The NVivo 12 software was used to further examine and generate state-of-the-art findings. The analysis of the findings of the study was confirmed by the participants through a small conference. The audio files of the athletes were deleted to uphold the protection and confidentiality of the participants

\section{Findings}

The findings of the study are presented into three themes: recognizing own limitations, identifying the effects of the recognized limitations, and determining the needed adjustments for the adaptability of female basketball athletes in DOSCST.

\section{Recognizing own limitations}

Figure 1 is Word Cloud of the decoded IDI for 
recognizing its own limitations. Being a student-athlete, many of them preferred fun and enjoyment. The informants preferred to work with their team who were approachable, paid respect, and had a sense of mutual understanding. Moreover, strong bond relationship, mentoring, and teamwork were positive recognitions that came out from interviews. Other notable feelings recorded were being fine, chill, and happy as varsity and athletes in basketball.

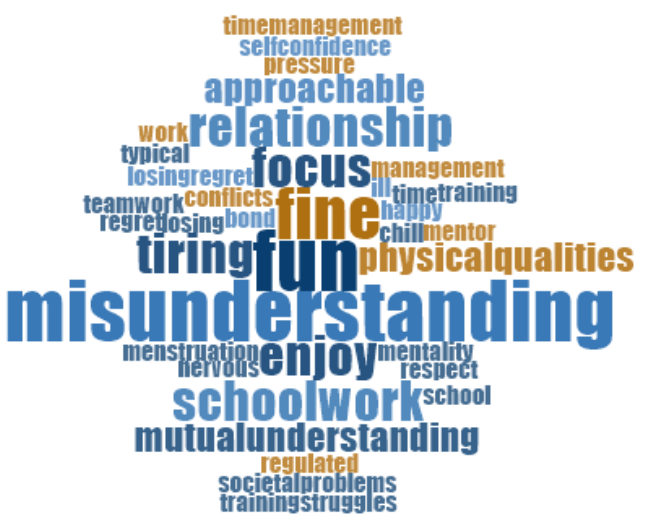

Figure 1. Word cloud of decoded IDI for recognizing own limitations

On the contrary, unanimous female athletes recognized misunderstanding among them which resulted in a lack of focus during playing. Team relationship, schoolwork, and being short were their own recognized limitations to play which hamper their sporting performance. One informant stated that the most difficult challenges she ever encountered were conflicts within the team especially in handling pressured games or one of their team is ill or absent which they could not perform better during the games. The feelings of loss, regret, and regulated to play during the tournament were most of the hardest moments to overcome and congenially accept the beauty of the game.

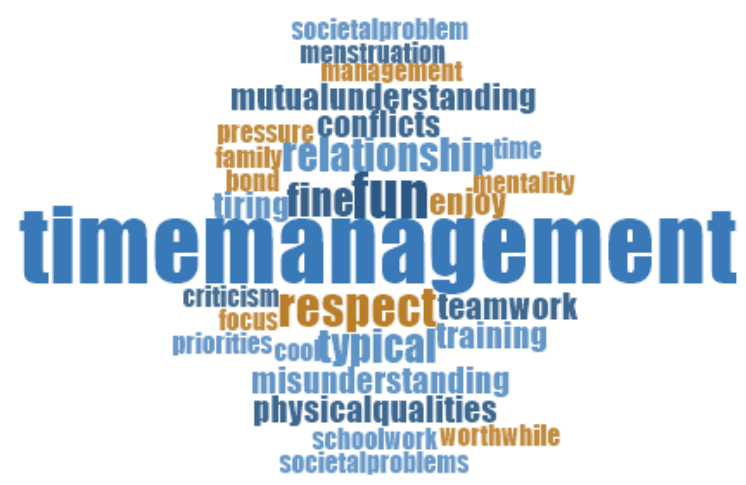

Figure 2. Word cloud of decoded FGD for recognizing own limitations

Figure 2 illustrates the word cloud of decoded FGD for recognizing own limitations being the female athletes in basketball. As a team, some informants found it fine and enjoyable as they earned respect and mutual understanding with regards to their teammates, coaches, families, teachers, friends, and spectators. Meanwhile, the data indicated that all informants recognized time management as their foremost building block as a team to training and playing. They also recognized the conflicts, misunderstanding, lack of focus, pressure, priorities (academics versus sports), and societal issues as their compounded challenges and experiences encountered.

\section{Identifying the effects of the recognized limitations}

Figure 3 presents the word cloud from the decoded IDI among female basketball athletes on how they identify the effects of the recognized limitations:

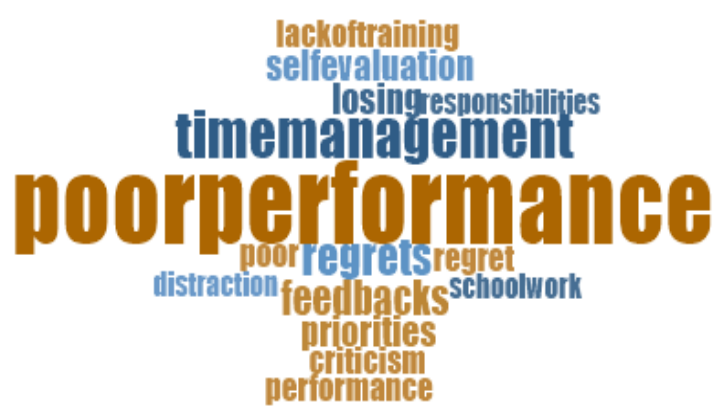

Figure 3. Word cloud of decoded IDI for identifying the effects of the recognized limitations

Time management plays a positive crucial effect in dealing with their limitations and multi-responsibilities as an athlete, student, sibling, and a person in the community. Apart from being an athlete, they considered their school priorities and responsibilities as inclined distractions to their training and game performance.

As we interviewed exclusively, most of the informants identified poor performance in the game due to their bad relationship with their teammates, coaches, families, teachers, and spectators. More identified effects were lack of training, feedbacking, criticism, and feeling of regrets in times of losing a game. One informant stood that self-evaluation is an identified effect to reflect the recognized problems.

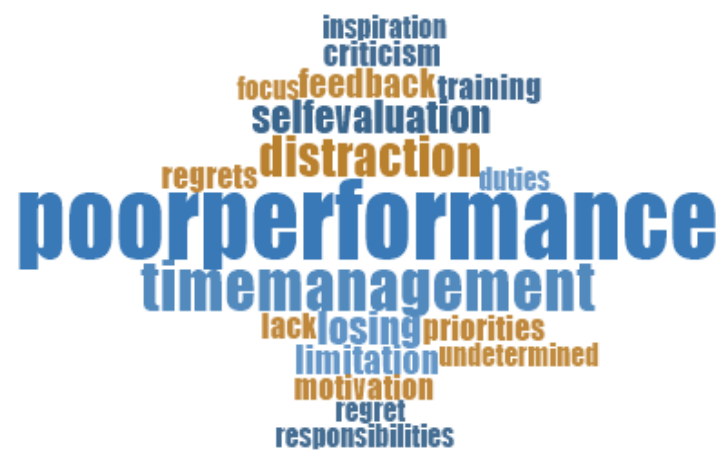

Figure 4. Word cloud of decoded FGD for identifying the effects of the recognized limitations 
Figure 4 reveals the word cloud of decoded FGD for identifying the effects of the recognized limitations. In a group discussion, most of the female athletes experienced having poor performance due to their recognized limitations. Difficulty in time management, lack of focus, being distracted, unbalanced priorities and duties were several of the effects of being student-athlete and towards their relationship with their coach, family, teachers, spectators, and teammates. Losing a game, feeling of regrets due to being undetermined and lack of training were some of the moments in which athletes thought they did not give their best in playing. Identifying the effects of recognized limitations were sought by athletes through self-evaluation, criticisms, and feedback.

\section{Determining the Athlete's Adaptability}

Figure 5 exhibits the word cloud of decoded IDI for determining the college female athlete's adaptability:

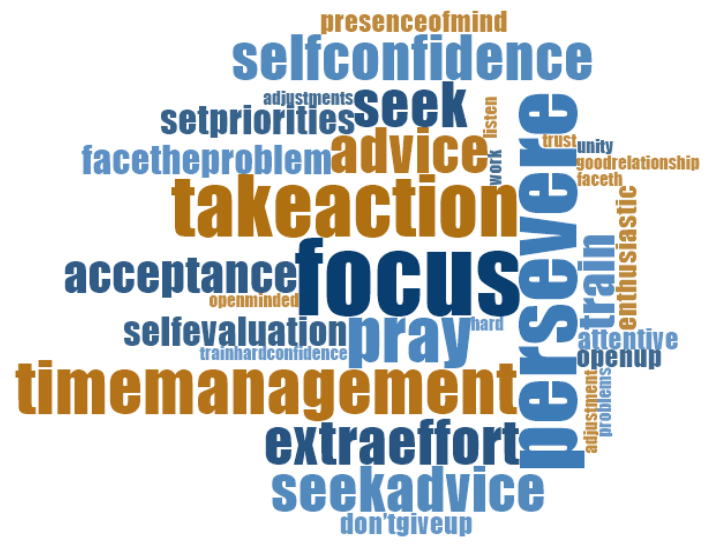

Figure 5. Word cloud of decoded IDI for determining the athlete's adaptability

Each informant determined focus in managing time as a student-athlete and with family, coach, team, and friends. In order to sustain the best performance, the female athletes persevere, make the extra effort, have the presence of mind, and training hard. They preferred adjusting, time management, and maintaining a good relationship. Meantime, self-evaluation, seeking advice, listening to being attentive, and opening to others were a few of the ways in finding a solution to their own problems. Moreover, athletes address their own limitations through acting and facing the problems, setting priorities, not giving up attitude, and having unity. All informants were determined to adapt to new challenges and performances in sports through prayers, acceptance, perseverance, and enthusiasm with self-confidence.

Figure 6 divulges the word cloud of decoded FGD for determining the college female athlete's adaptability:

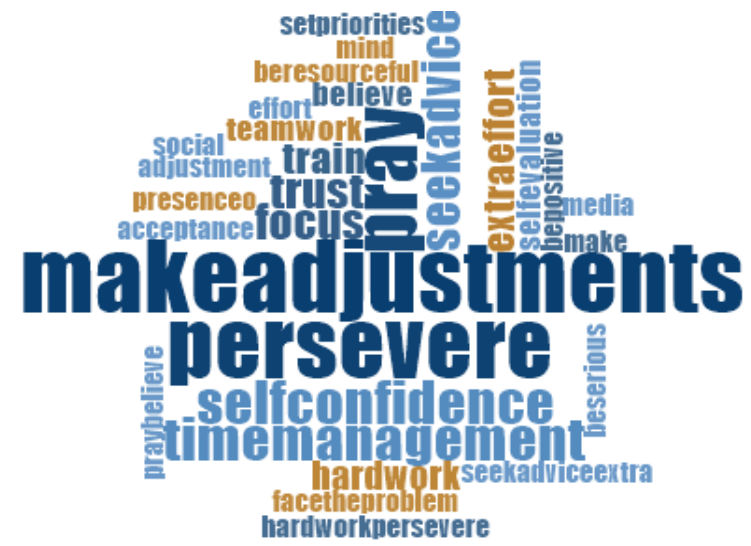

Figure 6. Word cloud of decoded FGD for determining the athlete's adaptability

Most of the informants adjusted their own limitations. They persevered and prayed as a shield to their problems. Training, hardworking, self-confidence, teamwork, effort, being positive, and resourceful were several ways in sustaining their best performance in playing basketball. The informants also considered time management, setting priorities, and social media as flexible tasks to assume being a student-athlete. Meanwhile, athletes seek advice from professionals and stakeholders, more focus on their goals, and self-evaluation were other means in addressing their own limitations. Moreover, athletes accept, believe, and trust themselves in encountering new circumstances and complex problems.

\section{The RID Adaptation Framework}

Figure 7 shows the RID Adaptation Framework designed by the authors to concretize the outcome of the investigation:

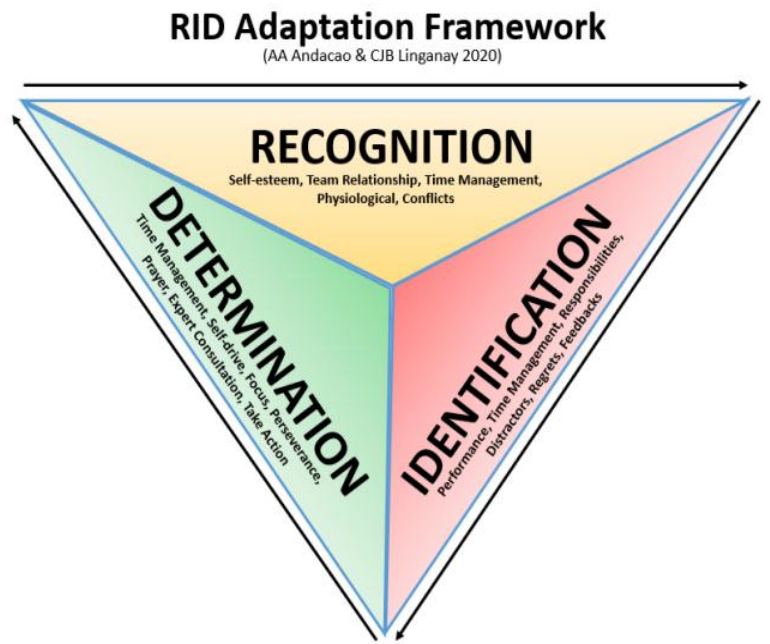

Figure 7. RID adaptation framework 
RID stands for Recognition, Identification, and Determination as female athletes' adaptation to play basketball. In this framework, athletes must recognize their self-esteem, team roles and relationship, time management, physiological, and present conflicts. The athletes must identify their performance in both academics and sports, being responsible and time-based student-athletes, manage distractors and regrets, and feedback mechanisms. After identifying the effects, the athletes now have self-drive, focus, perseverance, and adjusting time schedules. Prayer is the constant source of determination with expert consultation from coaches and another field of experts to improve sports and academic performance. Female athletes decide to take appropriate action to improve their sporting performance without hanging up their academics and quality of life rather than saying more words

We believe that this framework is a breakthrough and would be used in different fields of sports like this phenomenon and an avenue of new research for improvement.

\section{Discussion}

This paper explores and unveils the adaptability among female athletes in playing basketball. The encountered problems by each informant were different and could not speak to the overall female student-athletes. However, the themes can support the dearth of knowledge and thoughtful responsiveness among those employed in academic sports development for hands-on application and management.

The results can then be applied to administrators, educators, coaches, support personnel, athletes, and social and behavioural science researchers to sharpen and harness the experiences of this exceptional investigation. The adaptability among college basketball female athletes on how they leap their hurdles provides a significant contribution to enact positive adaptation inside the system of sports and the entire academy.

Adaptability among college female basketball athletes starts from high school [17]. Indeed, college freshman female student-athletes entered a new world and life and their experiences could be either personal success or failures in their academic and athletic careers [22]. College adjustments like academic and social stressors are generally common as they face more pressure and stress during the game tournaments as well as maintaining scholarship duties [23]. Student-athletes face various conflicts such as time management, academic issues, health problems, and identity relationships [24]. Adaptability is the highest possession that will be achieved by the athletes [25].

Recognizing own limitations among college female student-athletes in basketball reveals the first theme within the study. Limitations are boundaries that student-athletes must know and establish adjustment in a certain period of play and study. Most student-athletes experienced that they had not enough time to fully focus on both athletics and academics [26]. The female student-athletes encountered conflicts and misunderstanding between and among them, their coaches, teachers, families, friends, and spectators. Several authors found out these circumstances like personality traits of athletes [27] gender equity issues [28, 29, 30] struggled relationship with their coach [31], academic conflicts [24], health problems [24, 31] homesickness with their family and friends [22], and discrimination from sports fans [32].

Time management and the creation of a routine seem to be key components of a successful academic and sporting life balance. Some female student-athletes enjoyed it and found it fine as part of a team [33]. Many student-athletes enjoy playing sports for university due to the benefits from making friends, experience, staying active, and school spirit [34].

On the second theme, identifying the effects of the recognized limitations yields poor performance as gathered data information both from IDI and FGD. Insufficient physical training [35], academic stress [24, 36], lack of psychological well-being [36], lack of mental toughness [37] criticism [38], negative feedback, and lack of mentoring time [39] are some of the compounded regulations that need to be addressed effectively and efficiently. In order to counter the recognized problems, [40] found that self-assessment is the key to unlock the self-determination and self-efficacy of adolescent athletes in the environment of competitive sports. Moreover, time management plays an important role as one of the integrated skills of successful scholar-athletes [41].

The third theme determined the athlete's adaptability. [42] found that focus on playing basketball and dynamic adjustments in all conditions shape more of an adaptable athlete. [43] unearthed that courageous action achieved focus on goals and persistence beyond sports or competition. [42] believed in God as a source of all strength to overcome adversity through prayer both in and out of sports competition. Adaptability skills can be acquired both in attitude and action [43]. Social media [38], persistence in pursuit of a goal [43] and time management [48] are flexible tasks to accept as female athletes. Besides, coaches and parents are very influential in supporting academics and athletics [49].

The built RID Adaptation Framework is a newly generated model that speaks out the overall outcome of the study. This framework is parallel to the e-book [48] encouraged that high adaptability can be executed using the three-step model, such as recognizing the need for adaptation, understanding adaptation required, and necessary adaptation is made. The career construction model of adaptation of [49] could also connect to the framework to assist the connection between future work self-salience and proactive career behaviour among college student-athletes. Furthermore, the RID version framework 
is strengthened to the study conducted by [48] pointed out that incredible time management talents and healthy essential multi-task are two indicators to achieve athletically and academically success.

\section{Implications}

Time-based management is the common denominator of the findings being a college female basketball athlete. Adaptability is a skill that requires seamless order of action from the recognition of problems, identification of effects, and determination to take full control of the phenomena. The RID Adaptation Framework is an impetus to improve sports management in DOSCST. Henceforward, female athletes' adaptability comes from basic elements of personal and social adjustments that need proper streamlining, synergist action, and resilient support from different school disciplines. The authors put forward to study further by triangulating other team sports like football, softball, volleyball, and etcetera by applying this RID Adaption Framework to ascertain the potent model of female sports adaptation in the academic world.

\section{Acknowledgement}

The authors would love to thank the informants for their time and willingness to participate in the study. Appreciation is also given to the Davao Oriental State College of Science and Technology headed by President Emeritus and OIC-President Dr. Edito B. Sumile for approval of the study. Our indebted gratitude to Dr. Maria Gloria R. Lugo, Mr. Jumher Dave J. Pajarillaga, and Ms. Niña Alyssa M. Santiago for the nitty-gritty of this paper.

\section{REFERENCES}

[1] Martin, A. J., Nejad, H. G., Colmar, S., \& Liem, G. A. D. (2013). Adaptability: How students' responses to uncertainty and novelty predict their academic and non-academic outcomes. Journal of Educational Psychology, 105(3), 728. https://doi.apa.org/doiLanding?d oi $=10.1037 \% 2 \mathrm{Fa} 0032794$

[2] Shen, J. (2020, April 4). Cultivating adaptability is a pandemic coping skill.https://techcrunch.com/2020/04/04/ cultivating-adaptability-is-a-pandemic-coping-skill/

[3] Huggins, A., \& Randell, S. (2007, April). The contribution of sports to gender equality and women's empowerment. In a paper presented at the International Conference on Gender Equity on Sports for Social Change, Kigali. Retrieved March (Vol. 3, p. 2009).

[4] Yin, Y. K. (2019). Female athletes' experience of verbal aggression while playing basketball (Doctoral dissertation, John F. Kennedy University).
[5] Meléndez-Ostrov, M. C. (2018). Perceptions of Female Basketball Players of Color Regarding Their Athletic Coaches' Impact on Their Academic Success. University of Hartford.

[6] Stubbs, S. G. (2020). Female college student-athletes: Lived social and emotional experiences during the first year of college (Doctoral dissertation, Capella University).

[7] Jordan, P. (2019). Stacey Forsythe, Western Kentucky University Paula Upright, Western Kentucky University Rachel Mergenthal, Western Kentucky University. Kentucky Association of Health, Physical Education, Recreation and Dance, 73.

[8] de Haan, D., \& Norman, L. (2020). Mind the gap: The presence of capital and power in the female athletemale-coach relationship within elite rowing. Sports Coaching Review, 9(1), 95-118.

[9] Coston, A. F. (2020). Perceptions of the Academic Experience of Community College Student-Athletes (Doctoral dissertation, Morgan State University).

[10] Lydon, K., Madigan, S., \& Rankin, A. (2020). 244 Prevalence and burden of menstrual disorders in athletes: a questionnaire study. British Journal of Sports Medicine, 54(Suppl 1), A101.

[11] Reina Román, M., García-Rubio, J., Feu, S., \& Ibáñez, S. J. (2019). Training and competition load monitoring and analysis of women's amateur basketball by playing position: Approach Study. Frontiers in Psychology, 9, 2689. https://doi.org/10.3389/fpsyg.2018.02689.

[12] Pilis, K., Stec, K., Pilis, A., Mroczek, A., Michalski, C., \& Pilis, W. (2019). Body composition and nutrition of female athletes. Roczniki Państwowego Zakładu Higieny, 70(3).

[13] Gomez, J., Bradley J., \& Conway, P. (2018). The challenges of a high-performance student athlete, Irish Educational Studies, 37:3, 329-349,https://doi.org/10.1080/03323315.2 018.1484299

[14] Bolletino, C. (2020). Women athletes battling bias in the media. [Ebook]. https://digitalcommons.sacredheart.edu/ac adfest/2020/all/84/

[15] Ployhart, R., \& Bliese, P. (2006). Individual adaptability (I-ADAPT) theory: Conceptualizing the antecedents, consequences, and measurement of individual differences in adaptability. 10.1016/S1479-3601(05)06001-7.

[16] Zhou, M., \& Lin, W. (2016). Adaptability and life satisfaction: the moderating role of social support. Frontiers in Psychology, 7, 1134. https://www.frontiersin.org/article s/10.3389/fpsyg.2016.01134/full.

[17] Folle, A., Collet, C., Salles, W., \& Nascimento, J. (2016). Transition in the process of female basketball players' development. Revista Brasileira de Educação Física e Esporte. https://doi.org/10.1590/1807-5509201600020047 7.

[18] Fort-Vanmeerhaeghe, A., Montalvo, A., Latinjak, A., \& Unnithan, V. (2016). Physical characteristics of elite adolescent female basketball players and their relationship to match performance. Journal of Human Kinetics, 53(1), 167-178, https://doi.org/10.1515/hukin-2016-0020.

[19] Maslen, P. (2015, December 29). The social and academic benefits of team sports. Student Wellness. 
https://www.edutopia.org/discussion/social-and-academicbenefits-team-sports.

[20] Jackson, R. L., Drummond, D. K., \& Camara, S. (2007). What is qualitative research?. Qualitative Research Reports in Communication, 8(1), 21-28. https://www.tandfonline.c om/doi/abs/10.1080/17459430701617879.

[21] Creswell, J. W. (2012). Education research; planning, conducting, evaluating, quantitative and qualitative research. Pearson Education, Inc.

[22] Schullstrom, K. (2019). The lived experience of a freshman female collegiate student-athlete. Theses and Dissertations. 2686. https://rdw.rowan.edu/etd/2686.

[23] Drum, J., Ladda, S., Geary, C., \& Fitzpatrick, C. (2014). Athlete and non-athlete adjustment to college. Metropolitan Universities, 25(1), 39-62.

[24] Henrion, K. J. (2009). Key challenges facing student athletes and connections to their choice of major. Dissertations. 668. https://scholarworks.wmich.edu/dissert ations/668.

[25] Williams, P. (2019, November 14). In her own words: A survival guide to being a two-sport student-athlete. Women's Basketball. https://www.kstatesports.com/news/ 2019/11/14/womens-basketball-in-her-own-words-a-surviv al-guide-to-being-a-two-sport-student-athlete.aspx.

[26] Stevens, R. E., Loudon, D. L., Yow, D. A., Bowden, W. W., \& Humphrey, J. H. (2013). Stress in college athletics: Causes, consequences, coping. Routledge.

[27] Myers, K. M. (1991) A Comparison of personality traits of female interscholastic athletes and female intercollegiate athletes involved in basketball and softball. Masters Theses. 2245. https://thekeep.eiu.edu/theses/2245.

[28] Senne, J. A. (2016). Examination of gender equity and female participation in sport. The Sport Journal, 19, 1-9.

[29] Caroll, A. (2020). Why it's hard to be a female athlete. Athlete Network. https://an.athletenetwork.com/blog/whyits-hard-to-be-a-female-athlete.

[30] Yeoward-Dodson, J. (2020). Female athletes' experiences of body surveillance, body shame, depression symptoms, and self-compassion. (Doctoral Dissertation, The University of Memphis).

[31] Saxe, K. A. P. (2015). The Lived Experience of the Collegiate Female Student-Athlete. Master's Thesis, University of Tennessee. https://trace.tennessee.edu/utk_gr adthes $/ 3404$.

[32] Scheadler, T., \& Wagstaff, A. (2018). Exposure to women's sports: Changing attitudes toward female athletes. The Sport Journal, 19, 1-17.

[33] Pato, A. S., Isıdori, E., Calderón, A., \& Brunton, J. (2017). An innovative European sports tutorship model of the dual career of student-athletes. UCAM.

[34] Ridenhour, C. (2016, October 5). Being a student-athlete: What is it like? The Cabrini Blog.https://www.cabrini.edu/ blog/what-is-it-like-being-a-student-athlete.
[35] Kasabova, L. (2020). Influence of a training model for the development of the speed-strength qualities of female students from the university of national and world economy practicing basketball. Trakia Journal of Sciences, 18(1), 825-829.

[36] Jones, B. J., Kaur, S., Miller, M., \& Spencer, R. (2020). Mindfulness-Based Stress Reduction Benefits Psychological Well-Being, Sleep Quality, and Athletic Performance in Female Collegiate Rowers. Frontiers in Psychology, 11, 2373.

[37] Sartika, D., Berliana, B., Komarudin, K., Simbolon, M., Hamzah, A., \& Astuti, P. (2020). Increasing the mental toughness through match simulations in a basketball game. In 4th International Conference on Sport Science, Health, and Physical Education (ICSSHPE 2019) (pp. 148-151). Atlantis Press.

[38] Alexander, B. (2020). How Student-Athletes' Self-Esteem and Performance Are Influenced by Social Media Sports Fandom (Doctoral dissertation, Syracuse University).

[39] Kamachi, K. D. (2020). Leading, coaching, and mentoring: A study of coach-athlete relationships as associated factors in performance. Theses and Dissertations. 1175.

[40] Knight, A. (2020). Using self-assessment to build self-efficacy and intrinsic motivation in athletes: a mixed methods explanatory design on female adolescent volleyball players. The Qualitative Report, 25(2), 320-346. https://nsuworks.nova.edu/tqr/vol25/iss2/4.

[41] Cross, J. L., \& Fouke, B. (2019). Redefining the Scholar-Athlete. Frontiers in Sports and Active Living, 1, 10

[42] Semograd, M. L. (2020). Migration and adaptation experiences of American basketball athletes in Greece: A phenomenological study based on the cultural transition model. (Doctoral dissertation, University of Thessaly).

[43] Konter, E., Kueh, Y. C., \& Kuan, G. (2020). Courage in Competition: Adaptation of the Sports Courage Scale for American English and Validation of the Factor Structure with Student-Athletes at Clemson University. International Journal of Environmental Research and Public Health, 17(13), 4834

[44] Wiese-Bjornstal, D. M. (2019). Christian beliefs and behaviours as health protective, resilience, and intervention factors in the context of sport injuries. Sport psychology and Christianity: Welfare, performance and consultancy, 54-70.

[45] Half, R. (2020). Adaptability skills. https://www.roberthal f.co.nz/career-advice/career-development/adaptability-skill $\mathrm{s}$

[46] Sherry, M., \& Zeller, K. (2014). Gender and motivation: A study of the athletic and academic motivations of division I female college basketball players. Women's Studies, 43(1), 73-92.

[47] James, O. D. (2020). Investigating Student-athlete Identity and Academic Engagement at a Division I University: The Role of Coaches and Peers.

[48] McKeown, M. (2012). Adaptability: The art of winning in an age of uncertainty. Kogan Page Publishers. 
[49] Lu, W. C. (2020). Future work-self salience and proactive career behavior among college student-athletes in Taiwan: A career construction model of adaptation. Journal of
Hospitality, Leisure, Sport \& Tourism Education, 27, 100259. 